\title{
Commentary Challenges to the development of antigen-specific breast cancer vaccines
}

\author{
Matthew J Scanlan* and Dirk Jäger ${ }^{\dagger}$ \\ *Ludwig Institute for Cancer Research, New York, USA \\ †Il Medizinische Klinik, Frankfurt, Germany
}

\begin{abstract}
Correspondence: Mathew Scanlan, Ludwig Institute for Cancer Research, New York Branch of Human Cancer Immunology at Memorial Sloan-Kettering Cancer Center, 1275 York Avenue, New York, NY 10021. Tel: +1 212639 8481; fax: +1 2127173100 ;

e-mail: scanlanm@mskcc.org
\end{abstract}

Received: 14 November 2000

Breast Cancer Res 2001, 3:95-98

Accepted: 5 December 2000

(C) 2001 BioMed Central Ltd

Published: 11 January 2001

(Print ISSN 1465-5411; Online ISSN 1465-542X)

\begin{abstract}
Continued progress in the development of antigen-specific breast cancer vaccines depends on the identification of appropriate target antigens, the establishment of effective immunization strategies, and the ability to circumvent immune escape mechanisms. Methods such as $T$ cell epitope cloning and serological expression cloning (SEREX) have led to the identification of a number target antigens expressed in breast cancer. Improved immunization strategies, such as using dendritic cells to present tumor-associated antigens to $T$ lymphocytes, have been shown to induce antigen-specific $T$ cell responses in vivo and, in some cases, objective clinical responses. An outcome of successful tumor immunity is the evolution of antigen-loss tumor variants. The development of a polyvalent breast cancer vaccine, directed against a panel of tumor-associated antigens, may counteract this form of immune escape.
\end{abstract}

Keywords: cancer vaccines, dendritic cells, immunotherapy, tumor antigens

\section{Introduction}

Convincing evidence for immune recognition of cancer in the autologous host has been provided by the identification of human tumor antigens $[1,2]$ and by the verification of cancer immunesurveillance [3]. Cancer vaccines are a direct application of this knowledge and are based on the principle that a rigorous autotumorlytic immune response can be induced in cancer patients by immunization with tumor-associated antigens. Successful development of immunotherapeutic breast cancer vaccines hinges on the identification of appropriate target antigens and the establishment of effective immunization strategies, as well as on our ability to devise methods to circumvent immune escape mechanisms utilized by the evolving tumor. Preliminary progress in meeting these challenges is being made, as demonstrated by the ability of cancer vaccines to induce antigen-specific $\mathrm{T}$ lymphocyte responses and objective clinical responses in cancer patients. Although the results of recent clinical trials are promising, it should be noted that these are early-stage vaccine trials involving small populations of mostly end-stage melanoma patients, and are subject to variable patient and tumor responses. Nevertheless, the lessons learned from these studies can now be applied to the development of therapeutic breast cancer vaccines.

\section{Target molecules for antigen-specific breast cancer vaccines}

Both immunogenicity in cancer patients and restricted tissue expression are characteristics used to define anti- 
Table 1

\begin{tabular}{|c|c|c|}
\hline Target antigen & Expression in breast cancer & Reference \\
\hline \multicolumn{3}{|l|}{ Differentiation antigens } \\
\hline Carcinoembryonic antigen & $50 \%$ & {$[5]$} \\
\hline NY-BR-1 & $80 \%$ & [26] \\
\hline \multicolumn{3}{|l|}{ Cancer-testis antigens } \\
\hline NY-ESO-1 & $24 \%$ & {$[27]$} \\
\hline MAGE-1 & $8 \%$ & [27] \\
\hline MAGE-3 & $14 \%$ & [27] \\
\hline BAGE & $2 \%$ & [27] \\
\hline GAGE & $8 \%$ & [27] \\
\hline SCP-1 & $31 \%$ & {$[27]$} \\
\hline SSX-1 & $12 \%$ & [27] \\
\hline SSX-2 & $8 \%$ & [27] \\
\hline SSX-4 & $14 \%$ & [27] \\
\hline CT-7 & $30 \%$ & [28] \\
\hline \multicolumn{3}{|l|}{ Amplified/overexpressed antigens } \\
\hline Her2/neu & $40 \% 1$ & [29] \\
\hline NY-BR-62 & $60 \%{ }^{1}$ & [30] \\
\hline NY-BR-85 & $90 \% 1$ & [30] \\
\hline Tumor protein D52 & $60 \%{ }^{1}$ & [30] \\
\hline \multicolumn{3}{|l|}{ Mutational antigens } \\
\hline p53 & $17 \%^{2}$ & [31] \\
\hline
\end{tabular}

genic targets for cancer vaccines. Immunological methods of gene discovery, such as CD8+ and CD4+ T cell epitope cloning $[1,4]$ and serum antibody expression cloning (SEREX) [2], have led to the identification of tissue-restricted tumor antigens that are recognized by the immune systems of cancer patients and have added to the list of target antigens applicable to breast cancer (Table 1). These antigens fall into several categories, such as differentiation antigens, cancer-testis antigens, amplified/overexpressed gene products, and mutational antigens. One of the first target molecules to be examined in the context of a breast cancer vaccine is carcinoembrionic antigen (CEA), a differentiation antigen of the gut, expressed exclusively in normal colonic epithelium and approximately $50 \%$ of breast cancers [5]. With regard to clinical trials, Morse and colleagues have observed objective responses in patients with metastatic disease, including breast cancer, following immunization with dendritic cells (see below) pulsed with an human leukocyte antigen (HLA)-A2 restricted peptide of CEA [6]. Recently, a new differentiation antigen of the breast, NY-BR-1, was identified by SEREX analysis and was found to be expressed exclusively in normal testis and breast, as well as in $80 \%$ of breast cancers (Jäger et al, manuscript submitted). NYBR-1 is recognized by high titered serum IgG antibodies present in breast cancer patients, and its ability to induce a cellular immune response is under investigation.
Cancer-testis antigens represent a group of immunogenic proteins expressed exclusively in normal germ cells of the testis and embryonic ovary, and a percentage of various cancers. The melanoma antigens MAGE, BAGE, and GAGE are prototype cancer-testis antigens, first identified by cloning epitopes recognized by CD8+ T lymphocytes of melanoma patients $[1,7]$. SEREX analysis has also led to the identification of cancer testis antigens, including New York Esophageal-1 (NY-ESO-1), cancer testis-7 (CT-7), and the synovial sarcoma-x (SSX) family of antigens [8]. The enormous potential of CT antigens as vaccine targets is based on their restricted expression pattern and their high frequency of immunogenicity in cancer patients. Results of recent clinical trials using NY-ESO-1 [9] and MAGE-3 [10] as target antigens have been promising in terms of inducing antigen-specific T cells in vivo and, in some cases, concomitant disease regressions.

Mutated and amplified gene products represent another group of target antigens. The Her-2/neu oncogene is amplified in approximately $40 \%$ of breast cancers, and Her$2 /$ neu-specific $T$ cell responses have been observed in patients vaccinated with major histocompatibility (MHC) class II binding peptides derived from Her-2/neu [11]. The p53 tumor suppressor gene is frequently mutated in breast cancer and is associated with an autologous antibody response in breast cancer patients [12]. The large number of different p53 mutations makes targeting mutated p53 epitopes impractical. On the other hand, mutations increase the cellular half-life of p53, causing it to be overexpressed in cancer, indicating that immunization with wild type p53 may be an alternative. In fact, cytotoxic T lymphocyte (CTL) clones reactive against wild type p53 were generated from precursors present in the peripheral blood lymphocytes of healthy individuals, and were capable of lyzing several human tumor cell lines [13]. Three additional antigens recognized by the humoral immune system of breast cancer patients, NY-BR-62, NY-BR-85, and tumor protein D52, were found to be overexpressed in $60 \%$, $90 \%$, and $60 \%$ of breast cancers, respectively (Scanlan et al, manuscript submitted). Their significance in relation to breast cancer vaccines is being investigated.

\section{Immunization strategies}

Target antigens must first be presented as processed peptides bound to MHC class I and class II molecules. Recognition of these MHC-peptide complexes on the surface of antigen presenting cells (APCs) by antigen-specific $T$ lymphocytes, together with additional co-stimulation, leads to the proliferation of antigen-specific CD8+ and CD4+ T cells capable of lytic and immunostimulatory functions. Many antigen-specific cancer vaccines have been prepared as MHC class I binding peptides and administered intradermally, along with adjuvant and cytokines, in order to enhance uptake by APCs and augment the immune response. Recently, a MAGE-3 peptide vaccine 
yielded encouraging clinical results [14]. In this study, 7 out of 25 melanoma patients showed significant tumor regressions following vaccination, although there was no evidence of a strong CTL response against the MAGE-3 peptide in these responding patients.

Improvements in the delivery and presentation of target antigens are ongoing and include such strategies as continuous antigen administration by lymph node perfusion (Kundig, personal communication), direct targeting of APCs with recombinant Listeria monocytogenes that has been engineered to express tumor-associated antigens [15], and dendritic cell (DC) vaccines [16]. DCs are highly proficient APCs, expressing elevated levels of $\mathrm{MHC}$ class I and class II molecules, as well as important co-stimulatory molecules, and they also produce a variety of immunostimulatory cytokines [16]. DCs can be generated in vitro from precursors present in peripheral blood and subsequently used to present tumor antigens in vivo, when pulsed with antigenic peptide or transfected with DNA constructs encoding appropriate antigens. Several clinical trials employing DC vaccines have been carried out and the results have been promising $[6,11,17]$. With regard to epithelial cancers, Murphy and colleagues used DCs pulsed with HLA-A2 binding peptides derived from prostate-specific membrane antigen to treat patients with prostate cancer and observed significant clinical responses in 8 out of 33 vaccinated patients [18], and in a subset of these responders, cytokine secretion and CTL activity was detected against the immunizing peptide [19].

Current methods of adoptive immunotherapy rely on in vitro immunization, whereby tumor infiltrating lymphocytes are harvested from surgical specimens and propagated in vitro in the presence of interleukin-2 (IL-2) and appropriate antigen. The resultant CTL clones are then reintroduced into the autologous patient. Encouraging results have been obtained with this method as well. In one such study, CTLs specific for the melanocyte differentiation antigen gp100 were generated by cultivating tumor infiltrating lymphocytes in the presence of interleukin-2 and gp100. Upon infusion of these CTLs into autologous melanoma patients, significant tumor regressions were observed [20].

Other immunization strategies include the use of DNA vaccines, either in the form of viruses (adenovirus, vaccinia virus) or naked DNA, to deliver genes encoding tumor antigens [21]. Such vectors contain the coding sequence for a particular target antigen and may also contain sequences encoding targeting motifs for $\mathrm{MHC}$ class I and class II pathways, immunostimulatory cytokines, and costimulatory molecules. One major concern with using viral vectors is the presence of neutralizing antiviral antibodies in the recipient, resulting from a prior immunization (eg smallpox vaccine), which would negate vaccination.

\section{Circumventing the tumor's immunological escape mechanisms}

In response to immunesurveillance or effective immunotherapy, tumor cells may evolve mechanisms that allow them to escape immune recognition. Such immunoselection can cause an outgrowth of tumor cell populations that have lost expression of a given target antigen [22]. The use of polyvalent vaccines, specific for several tumorassociated antigens, or vaccination with antigens required by the tumor for maintenance of its malignant phenotype (eg telomerase), may circumvent this form of immune escape. Tumor cells also secrete immunosuppressive cytokines such as transforming growth factor (TGF)- $\beta$ and IL-10, which can inhibit $T$ lymphocyte effector function. Animal models have shown that it is possible to block the inhibitory activity of TGF- $\beta$ by using an antibody against TGF- $\beta$ in conjunction with IL-2 [23]. Similarly, blocking of inhibitory co-stimulation, such as the interaction between the CTLA- 4 molecule on the surface of activated T cells and the B7 molecule on APCs, may augment the immune response [24]. An additional and quite significant form of immune escape is the ability of tumor cells to evolve mechanisms that impede antigen processing and presentation. Much attention is currently being focused on the proteosome, a key component of the antigen processing pathway, and it is hoped that these studies will generate a more thorough understanding of antigen presentation, enabling us to design strategies to thwart this mode of immune escape [25].

\section{Conclusion}

Although active immunotherapy directed against specific target molecules expressed in cancer offers promise for cancer treatment, a considerable amount of research needs to be carried out before it can be considered a viable therapeutic option. Identification of additional target antigens will increase the number of individuals that can be treated with cancer vaccines and allow for the development of polyvalent vaccines, which may offset antigen loss by tumors. Different immunization strategies are the subject of current immunotherapy trials, and by placing emphasis on the route of specific immunostimulation these trials may result in enhanced immune responses and clinical outcomes. Finally, it is important that patient monitoring schemes be enhanced and standardized since it will allow for improved measurement of patient responses and direct comparison of different clinical trials.

\section{Acknowledgements}

The authors would like to thank Dr Lloyd J Old for his helpful comments regarding the preparation of this manuscript.

\section{References}

1. van der Bruggen $P$, Traversari $C$, Chomez $P$, Lurquin $C$, De Plaen $E$, Van den Eynde $B$, Knuth $A$, Boon $T$ : A gene encoding an antigen recognized by cytolytic $\mathrm{T}$ lymphocytes on a human melanoma. Science 1991, 254:1643-1647. 
2. Sahin U, Türeci Ö, Schmitt H, Cochlovius B, Johannes T, Schmits R, Stenner F, Luo G, Schobert I, Pfreundschuh M: Human neoplasms elicit multiple specific immune responses in the autologous host. Proc Natl Acad Sci USA 1995, 92:11810-11813.

3. Kaplan DH, Shankaran V, Dighe AS, Stockert E, Aguet M, Old LJ, Schreiber RD: Demonstration of an interferon gamma-dependent tumor surveillance system in immunocompetent mice. Proc Natl Acad Sci USA 1998, 95:7556-7561.

4. Wang RF, Wang X, Atwood AC, Topalian SL, Rosenberg, SA: Cloning genes encoding MHC class II-restricted antigens: mutated CDC27 as a tumor antigen. Science 1999, 284:13511354.

5. Hodge JW: Carcinoembryonic antigen as a target for cancer vaccines. Cancer Immunol Immunother 1996, 43:127-134.

6. Morse MA, Deng Y, Coleman D, Hull S, Kitrell-Fisher E, Nair S, Schlom J, Ryback ME, Lyerly HK: A Phase I study of active immunotherapy with carcinoembryonic antigen peptide (CAP1)-pulsed, autologous human cultured dendritic cells in patients with metastatic malignancies expressing carcinoembryonic antigen. Clin Cancer Res 1999, 5:1331-1338.

7. Van den Eynde BJ, van der Bruggen P: T cell defined tumor antigens. Curr Opin Immunol 1997, 9:684-693.

8. ChenYT, Scanlan MJ, Obata Y, Old L: Identification of human tumor antigens by serological expression cloning. In Principles and Practice of Biologic Therapy of Cancer. Edited by Rosenberg SA. Philadelphia PA: Lippincott Williams \& Wilkins, 2000:557-570

9. Jäger $E$, Gnjatic $S$, Nagata $Y$, Stockert E, Jäger D, Karbach J, Neumann A, Rieckenberg J, Chen YT, Ritter G, Hoffman E, Arand $M$, Old LJ, Knuth A: Induction of primary NY-ESO-1 immunity: CD8+ T lymphocyte and antibody responses in peptide-vaccinated patients with NY-ESO-1+ cancers. Proc Natl Acad Sci USA 2000, 97:12198-12203.

10. Thurner B, Haendle I, Roder C, Dieckmann D, Keikavoussi P, Jonuleit H, Bender A, Maczek C, Schreiner D, von den Driesch P, Brocker EB, Steinman RM, Enk A, Kampgen E, Schuler G: Vaccination with mage-3A1 peptide-pulsed mature, monocytederived dendritic cells expands specific cytotoxic $T$ cells and induces regression of some metastases in advanced stage IV melanoma. J Exp Med 1999, 190:1669-1678.

11. Disis ML, Grabstein KH, Sleath PR, Cheever MA: Generation of immunity to the HER-2/neu oncogenic protein in patients with breast and ovarian cancer using a peptide-based vaccine. Clin Cancer Res 1999, 5:1289-1297.

12. Soussi $\mathrm{T}: \mathrm{p} 53$ Antibodies in the sera of patients with various types of cancer: a review. Cancer Res. 2000, 60:1777-1788.

13. Chikamatsu K, Nakano K, Storkus WJ, Appella E, Lotze MT, Whiteside TL, DeLeo AB: Generation of anti-p53 cytotoxic T lymphocytes from human peripheral blood using autologous dendritic cells. Clin Cancer Res 1999, 5:1281-1288.

14. Marchand $M$, van Baren $N$, Weynants $P$, Brichard V, Dreno $B$, Tessier MH, Rankin E, Parmiani G, Arienti F, Humblet $Y$, Bourlond A, Vanwijck R, Lienard D, Beauduin M, Dietrich PY, Russo V, Kerger J, Masucci G, Jäger E, De Greve J, Atzpodien J, Brasseur $F$, Coulie PG, van der Bruggen $P$, Boon T: Tumor regressions observed in patients with metastatic melanoma treated with an antigenic peptide encoded by gene MAGE-3 and presented by HLA-A1. Int J Cancer 1999, 80:219-230

15. Paterson $Y$, Ikonomidis G: Recombinant Listeria monocytogenes cancer vaccines. Curr Opin Immunol 1996, 8:664-669.

16. Mule JJ: Dendritic cells: at the clinical crossroads. J Clin Invest 2000, 105:707-708.

17. Nestle FO, Alijagic S, Gilliet M, Sun Y, Grabbe S, Dummer R, Burg G, Schadendorf D: Vaccination of melanoma patients with peptide- or tumor lysate-pulsed dendritic cells. Nat Med 1998, 4:328-332.

18. Murphy GP, Tjoa BA, Simmons SJ, Jarisch J, Bowes VA, Ragde $H$, Rogers M, Elgamal A, Kenny GM, Cobb OE, Ireton RC, Troychak MJ, Salgaller ML, Boynton AL: Infusion of dendritic cells pulsed with HLA-A2-specific prostate-specific membrane antigen peptides: a phase II prostate cancer vaccine trial involving patients with hormone-refractory metastatic disease. Prostate 1999, 38:73-78.

19. Lodge PA, Jones LA, Bader RA, Murphy GP, Salgaller ML: Dendritic cell-based immunotherapy of prostate cancer: immune monitoring of a phase II clinical trial. Cancer Res 2000, 60: 829-833.
20. Kawakami Y, Eliyahu S, Jennings C, Sakaguchi K, Kang X, Southwood S, Robbins PF, Sette A, Appella E, Rosenberg SA: Recognition of multiple epitopes in the human melanoma antigen gp100 by tumor-infiltrating $T$ lymphocytes associated with in vivo tumor regression. J Immunol 1995, 154:3961-3968.

21. Restifo NP: The new vaccines: building viruses that elicit antitumor immunity. Curr Opin Immunol 1996, 8:658-663.

22. Jäger $E$, Ringhoffer $M$, Karbach $J$, Arand $M$, Oesch $F$, Knuth $A$ : Inverse relationship of melanocyte differentiation antigen expression in melanoma tissues and CD8+ cytotoxic-T-cell responses: evidence for immunoselection of antigen-loss variants in vivo. Int J Cancer 1996, 66:470-476.

23. Wojtowicz-Praga S, Verma UN, Wakefield L, Esteban JM, Hartmann D, Mazumder A: Modulation of B16 melanoma growth and metastasis by anti-transforming growth factor beta antibody and interleukin-2. J Immunother Emphasis Tumor Immunol 1996, 19:169-175.

24. Leach DR, Krummel MF, Allison JP: Enhancement of antitumor immunity by CTLA-4 blockade. Science 1996, 271:17341736.

25. Morel S, Levy F, Burlet-Schiltz O, Brasseur F, Probst-Kepper M, Peitrequin AL, Monsarrat B, Van Velthoven R, Cerottini JC, Boon T, Gairin JE, Van den Eynde BJ: Processing of some antigens by the standard proteasome but not by the immunoproteasome results in poor presentation by dendritic cells. Immunity 2000, 12:107-117.

26. Jäger $D$, Stockert $E$, Gure $A O$, Scanlan $M J$, Karbach J, Jäger $E$, Knuth A, Old LJ, Chen YT: Identification of a tissue-specific transcription factor in breast tissue by serological screening of a breast cancer library. Submitted 2000.

27. Sahin U, Tureci O, Chen YT, Seitz G, Villena-Heinsen C, Old LJ, Pfreundschuh M: Expression of multiple cancer/testis (CT) antigens in breast cancer and melanoma: basis for polyvalent CT vaccine strategies. Int J Cancer 1998, 78:387-389.

28. Chen YT, Gure AO, Tsang S, Stockert E, Jager E, Knuth A, Old ᄂ: Identification of multiple cancer/testis antigens by allogeneic antibody screening of a melanoma cell line library. Proc Natl Acad Sci USA 1998, 95:6919-6923.

29. Disis ML, Calenoff E, McLaughlin G, Murphy AE, Chen W, Groner B, Jeschke M, Lydon N, McGlynn E, Livingston RB, Moe R, Cheever MA: Existent T cell and antibody immunity to HER$2 /$ neu protein in patients with breast cancer. Cancer Res 1994, 54:16-20.

30. Scanlan MJ, Gout I, Gordon CM, Williamson B, Stockert E, Gure AO, Jäger D, Chen YT, Mackay A, O'Hare MJ, Old LJ: Humoral immunity to human breast cancer: antigen definition and quantitative analysis of mRNA expression. Submitted 2000.

31. Runnebaum IB, Nagarajan M, Bowman M, Soto D, Sukumar S: Mutations in p53 as potential molecular markers for human breast cancer. Proc Natl Acad Sci USA 1991, 88:10657-10661. 